\title{
Early career teacher's approach to fraction equivalence in Grade 4: A dialogic teaching perspective
}

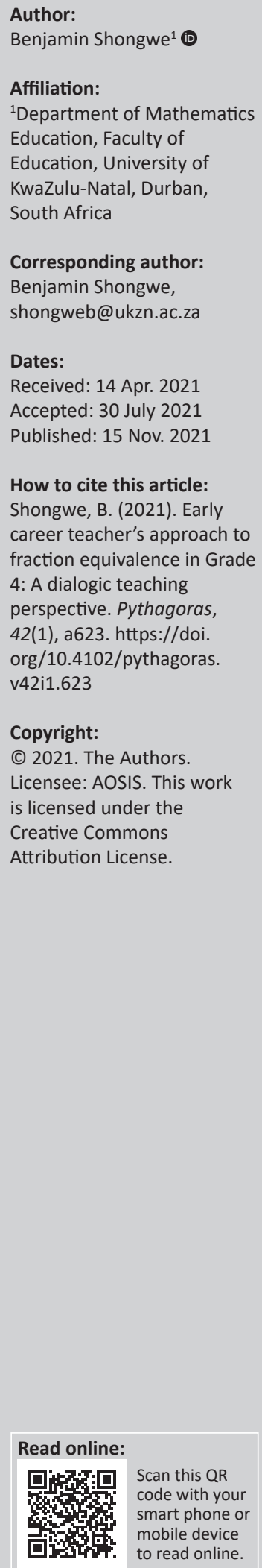

The research presented in this article reports on the results of a case study examining the classroom practice of one early career Grade 4 teacher (Nox, pseudonym) as she teaches equivalent fractions. The goal was to explore the ways and extent to which her instruction reflected a dialogical teaching approach, defined as a pedagogical approach underpinned by five specific principles that can be enacted through a range of possible talk strategies to achieve sustained participation of learners and thus enhance meaningful learning. I provide a pedagogical activity to illustrate to teachers how, by instigating and developing classroom talk in the primary classes, a dialogic teaching sequence may be implemented. However, the majority of the existing literature on dialogic teaching stems from studies conducted in Asian, European, and North American countries, whereas systematic research on dialogic teaching across international contexts remains limited. Nox was interviewed after obtaining observational data to seek clarity on some of the observed instructional practices. Analysis of transcripts using the notion of dialogic teaching as a theoretical lens revealed that there was little evidence of Nox's attempts to use talk to make learning of equivalent fractions a cumulative process. In addition, time constraint was the most significant factor in Nox's teaching of equivalent fractions: she considered the curriculum too congested. Implications are drawn for evaluating dialogic teaching in primary mathematics classrooms. Future, larger studies may shed light on the extent of these results and, if need be, a significant investment on initial teacher training may be necessary to underscore the value of dialogic teaching in enhancing meaningful learning of, at least, equivalent fractions.

Keywords: early career teacher; dialogic teaching; meaningful learning; equivalent fractions; Grade 4; generalisation; pedagogical tool; learners' ideas.

\section{Introduction}

Fractions is not only one of the most important topics in mathematics, but also one of the most multifaceted (Pedersen \& Bjerre, 2021). An important part of this domain of mathematics is fraction equivalence.

Meaningful learning of fraction equivalence is crucial for learners' success in algebra, a gatekeeper to post-school education 'and the careers such education affords' (Kilpatrick \& Izsák, 2008, p. 11). Learners' understanding of the fundamental concept of fraction equivalence should reflect more than just procedural knowledge of generating equivalent fractions; they should be able to make connections among symbols, models, pictures, and context (Wessel, 2020). Previous research has documented that meaningful learning of fractions by learners, particularly constructing or identifying equivalent fractions and the development of equivalent sets of fractions, has been met with difficulty (Aliustaoğlu, Tuna, \& Biber, 2018; Namkung, Fuchs, \& Koziol, 2018; Önal \& Yorulmaz, 2017; Pearn, 2003). Learners' difficulties with equivalent fractions date back decades ago. Cramer, Post and DelMas (2002) suggested that the difficulties are associated with mathematics instruction that tends to focus more on simple part-whole shading tasks, leaving little time to develop an understanding of the meaning of fractions in Grade 4. The reasonable conclusion to draw from this suggestion is that attention must be on the teacher. In fact, there is broad consensus that 'teacher quality is the single most important school variable influencing student achievement' (Organisation for Economic Co-operation and Development [OECD], 2005, p. 2). It is for these reasons that the study focused, in the main, on a teacher's instructional practices in the domain of equivalence.

In a study conducted by Jigyel and Afamasaga-Fuata'i (2007), it was found that most learners do not discuss ways of computing equivalent fractions unless prompted to do so. For example, Putra and Winsløw (2018) have pointed out that one of the main misconceptions of finding an equivalent 
fraction is that learners tend to add both numerator and denominator of a fraction by a positive integer (i.e., $\frac{\mathrm{a}}{\mathrm{b}}=\frac{\mathrm{a}+\mathrm{n}}{\mathrm{b}+\mathrm{n}}, n \in \mathbb{Z}^{+}$). Also, Van Hoof, Lijnen, Verschaffel and Van Dooren (2013) highlight the whole number bias, a term coined by $\mathrm{Ni}$ and Zhou (2005) to characterise learners' tendency to see the numerator and denominator as separate numbers. Put another way, learners tend to engage in an overextension of natural number principles (Obersteiner, Alibali, \& Marupidi, 2020). Pedersen and Bjerre (2021) attribute this common mistake to the fact that learners' first encounter with quantities involves natural numbers in which every number represents a unique quantity. As a consequence, $\mathrm{Ni}$ and Zhou (2005) point out, when learners subsequently encounter rational numbers, seemingly different numbers describe the same quantity in the fraction notation. An understanding of a fraction as a number that can be written in different but equivalent forms, for example, is a prerequisite for meaningful learning of equivalent fractions (Charalambous \& Pitta-Pantazi, 2007). Thus, meaningful learning of equivalent fractions is helpful in determining the number of fractions between, for example, $\frac{2}{5}$ and $\frac{3}{5}$ (Jigyel \& Afamasaga-Fuata'i, 2007). Still, it leads to utilisation of number line representations of fractions (Bright, Behr, Post, \& Wachsmuth, 1988).

Although direct teaching, ${ }_{1}^{1}$ defined here as teacher-directed instructional practice characterised by teaching of specific skills to learners, is effective in producing learning of basic mathematical skills (i.e. computation of amounts, sizes or other measurements involving addition and subtraction), dialogic teaching has been the focus of many investigations over the years because of the acknowledgement that it is of prime importance for teaching and learning in the classroom and beyond (Arend \& Sunnen, 2015). Most curricular documents have identified dialogic teaching as a desired means of teaching and learning (National Council of Teachers of Mathematics [NCTM], 2000; National Governors Association Center for Best Practices [NGA] \& Council of Chief State School Officers [CCSSO], 2010). Research studies have found that dialogic teaching engenders meaningful learning. For Baroody and Hume (1991), meaningful learning puts less emphasis on direct teaching and paper-and-pencil work but builds upon learners' informal strengths rather than treating them as blank slates (tabulae rasae). However, Hiebert and Grouws (2007) state that 'there is no reason to believe, based on empirical findings or theoretical arguments, that a single method of teaching is the most effective for achieving all types of learning goals' (p. 374), Alexander's (2020) notion of dialogic teaching is particularly touted as an approach that can achieve the best educational results because of its emphasis on the active and sustained participation of learners in classroom talk. Findings by Mercer and Sams (2006), Resnick, Asterhan and Clarke (2015), and Rojas-Drummond and Mercer (2004) from investigations of teachers' interactional strategies showed that dialogic teaching indeed achieves better learning

1.I follow Hiebert and Grouws (2007) in defining teaching as "classroom interactions among teachers and students around content directed toward facilitating students' achievement of learning goals' (p. 377). outcomes in cognitive domain (e.g. intellectual skills and verbal information) and affective domain (e.g. attitude and disposition to persevere). It is clear then that these two teaching orientations, namely direct teaching and dialogic teaching, would entail strikingly different visions of what 'good' teaching looks like in a mathematics classroom. In turn, they would in all likelihood have different effects on learning outcomes.

As the name suggests, dialogic teaching is described as teacher-led interactions with learners - one of the two main kinds of interaction, the other being learner-learner interactions (Mercer \& Sams, 2006). Seen in this light, dialogic teaching is founded on Vygotsky's (1978) sociocultural account of learning in which the teacher - the 'more knowledgeable other' - provides a 'scaffolding' for the development of understanding of mathematical practice ${ }^{2}$ and mathematical operations, procedures, terms, and concepts. Although there is some variation in the precise definition of the metaphor of 'scaffolding' among researchers, a key characterisation of this term is that a teacher provides a sensitive kind of help, which enables a learner engaged in a task to improve their competence and eventually achieve meaningful learning (Rojas-Drummond, Mercer, \& Dabrowski, 2001). Clearly, different researchers will use various terms to describe dialogic forms of teaching: Pappas and Varelas (2006) and Wells (1999) call it dialogic inquiry, Skidmore (2006) prefers to label it dialogical pedagogy, and for Van der Linden and Renshaw (2004) it is dialogic learning. In this article, dialogic teaching is used because Alexander's (2020) principles of dialogic teaching are grounded in the teacher's approach, in particular, their listening to a variety of learners' ideas and chaining them into coherent lines of thinking and understanding.

Prior to providing a review of literature, it will be helpful to define the notions of 'meaningful learning' and 'dialogic teaching', which are particularly clearer if they are contrasted with 'rote learning'. According to Ausubel (2012), meaningful learning is a function of a learner's disposition to relate symbolically expressed ideas (the learning task) in a nonarbitrary, and nonverbatim fashion, to already existing knowledge. In contrast, rote learning entails retention of learned material on a purely associative basis (e.g. memorising multiplication tables with no opportunities for learners to notice or to associate interrelations between 3 and 9 times tables, for example). Novak (2010) points out that meaningful learning is the facilitation of the construction of valid meanings and reconstruction of misconceptions (invalid meanings) in learners' cognitive structures. By 'cognitive structure' is meant knowledge organised through processing of new information for its appropriate retrieval in new contexts, as in novel mathematics problem-solving (Novak, 2002). As Schmidt (1993) argues, this knowledge is considered organised in a certain way, hence cognitive structure. This definition points to the connection between

2.By mathematical practice is meant mathematical activity involving plausible (inductive) reasoning, through which conjectures are generated, and demonstrative (deductive) reasoning that is formalised in proof (Reid, 2002). 
prior knowledge and dialogic teaching. However, it is important that I explicitly define what is meant by 'dialogic teaching'. Dialogic teaching is a term used to denote a pedagogical tool ${ }^{3}$ that harnesses the power of classroom talk to engage learners' prior knowledge, stimulate their thinking, advance their understanding, and expand their ideas in the mathematics classroom (Alexander, 2020). Mercer and Littleton (2007) describe dialogic teaching as 'that in which both teachers and pupils make substantial and significant contributions and through which children's thinking on a given idea or theme is helped to move forward' (p. 41). In this sense, as Alexander (2006) argues, dialogic teaching is structured classroom talk thus making it 'the true foundation of learning' (p. 9). In dialogic teaching, attention is paid to more than one point of view, more than one voice is heard in the classroom and there is 'interanimation' (exploration) of ideas (Bakhtin, 1981; Mortimer \& Scott, 2003). Indeed, it depicts a classroom practice in which the teacher's perspective is not prioritised; instead, learners and the teacher co-develop the object of the lesson (Arend \& Sunnen, 2015).

In short, given the complexity of educational contexts, it would be simplistic to assume that dialogic teaching would be suitable in all classrooms. The results in this article should broaden our knowledge of early career teachers' uptake of dialogic teaching as a framework that prioritises learners' ideas in the development of mathematical concepts. By doing so, the results should transform the links of dialogic teaching to equivalent fractions and thus improve teaching of equivalent fractions content.

\section{Purpose of the present study}

Previous research suggests that teaching approaches ${ }^{4}$ may vary across countries (Aliustaoğlu et al., 2018; Namkung et al., 2018; Önal \& Yorulmaz, 2017; Putra \& Winsløw, 2018). Moreover, the majority of the existing literature on dialogic teaching stems from studies conducted in Asian, European, and North American countries, whereas systematic research on dialogic teaching across international contexts remains limited. Thus, dialogic teaching strategies in some countries may not be generalisable to other educational contexts. Thus, we know little about how an early career teacher employs dialogic teaching to assist her Grade 4 learners in the quest to acquire meaningful learning of equivalent fractions in instructional practices. The purpose of this study was to explore the dialogic teaching strategies employed by one early career Grade 4 teacher. The analysis is grounded in Alexander's (2020) theoretical perspectives to broaden our understanding of dialogic teaching in classroom interactions and to transform its links to equivalent fractions. Equivalent fractions, a topic that has proved to be difficult to learn, provided the impetus for this study. Through a qualitative

3.Paraphrasing Watson and Mason (2005), I take 'pedagogical tool', in the context of mathematics education, to mean what a teacher uses as a 'window' into a learner's mind, which includes items such as worksheets, textbooks, handouts, manipulatives, technology, mobile device applications, etc.

4.I join Arbaugh and Benbunan-Fich (2006) in defining teaching approach as 'the extent to which the instructor is the focus of the educational process and the exten to which the instructor relies upon individually or group-oriented activities' (p. 435). analysis of observational and interview data, the following general research question was posed: How does an early career teacher engage her learners in meaningful learning and sustained participation during the teaching of equivalent fractions?

The remainder of this article is structured as follows. Having provided a brief background to the study, I elaborate on the literature pertaining to dialogic teaching and exemplify the kind of strategies that may partly characterise instruction on equivalent fractions. Then, I provide a framework guiding this study. Next, an analysis of the results is undertaken followed by a discussion in which I interweave the literature with the findings. On the basis of the findings, I end the article with implications for classroom practice and recommendations for future research.

\section{Literature review}

In recent years, many researchers in the field of education have shown interest in the work of Robin Alexander, David Ausubel, and Mikhail Bakhtin. These scholars have conceptualised terms like 'dialogic' and 'meaningful learning', which have gained increased attention in both mathematics and science education studies on classroom interactions. The term 'dialogic' has gained increased attention and classroom talk has become a key topic in educational sciences (Arend \& Sunnen, 2015). To situate the proposed study in current literature on classroom interactions, reference to the research work of these scholars is made. However, this review of literature does not pretend to provide an exhaustive overview of related research on classroom interactions; only research work related to dialogic theory will be reviewed. The basis for this approach is that these scholars' works centre around the notion of 'dialogic' as an approach to investigate or theorise about classroom interactions. Ausubel's theory of meaningful learning, refined by the work of Joseph Novak, is anchored in Piaget's (1964) constructivist perspectives. Alexander's (2006, 2020) 'dialogic teaching', the focus of the proposed study, builds on the foundational works of Bakhtin $(1981,2010)$.

\section{Research on dialogic teaching}

Teaching and learning is primarily concerned with the acquisition, retention, and use of information such as facts, propositions, principles, and vocabulary in the various disciplines (Ausubel, 2000). One way in which such processes take place involves the idea of dialogic teaching. In their seminal work, Sinclair and Coulthard (1975) proposed what can be thought of as the archetypal form of interaction between a teacher and a learner, particularly their identification of the structural feature of discourse usually known as the Initiation-Response-Feedback (IRF) exchange. For example:

Teacher: What is the capital of Peru? (I)

Student: Lima. (R)

Teacher: Yes, quite correct $(\mathrm{F})$ 
The IRF structure involves 'closed' questions in which there is only one answer, which is already known to the teacher. Although this structure does not typify the pattern of talk in all classroom activities (learners may ask questions of teachers, or of other learners), IRFs have been observed as a common feature in classrooms the world over (Mercer, 1995). Teachers' relentless questioning reduces the amount and variety of the verbal contributions that their learners can make in the classroom. They argue that this behaviour must have a detrimental effect on the intellectual activity of learners. Clearly, this comparison suggests that dialogic teaching is distinct from the 'speaking and listening' that characterises most interactions in classrooms.

In a study of Danish and Indonesian teachers' pedagogical approach to equivalent fractions, Putra and Winsløw (2018) found that Danish learners tend to argue that adding the same natural number to both the numerator and denominator gives another equivalent fraction. For example, one learner incorrectly argued that $\frac{3}{4}=\frac{3+5}{4+5}=\frac{8}{9}$. It is such learners' difficulty with equivalent fractions that definitely points to the need to investigate the efficacy of dialogic teaching as a more effective way to teach this important concept. Particular attention will be given to overcoming the difficulty learners have with the 'equivalence' idea, delaying the rule until there is meaningful learning of the concept of equivalent fractions (Gattegno, 2010).

Learners should understand why a procedure works prior to using it. During interviews with two preservice teachers, Shongwe (2014) found that teacher preparation programmes and beliefs strongly influence classroom talk. Mercer and Sams (2006) have found that teachers can act as important models for learners' own use of language for constructing knowledge, particularly when they use probes such as 'why' and 'what I heard you say was ...'. The 'why' question evokes reasoning about why learners took a particular approach in a task and can be very useful for revealing learners' perspectives on the task to the teacher and for stimulating their own reflection on it. Research studies in both science and mathematics education have repeatedly shown that the use of dialogic teaching strategies enhances meaningful learning (Alexander, 2020; Mortimer \& Scott, 2003; Rojas-Drummond et al., 2001).

\section{Current teaching approaches in classrooms}

Hogan, Nastasi and Pressley (2000) have shown that teacherled discussions and learner-learner discussions are two distinct processes in that the former is a more efficient means of attaining higher levels of meaning-making whereas the latter tends to be more exploratory. Similarly, Nathan and Knuth (2003) found that, when the teacher maintained a central role, the learner-led discussions increased considerably; however, at the expense of mathematical precision. For instance, one pair of learners working on equivalent fractions in Putra and Winsløw's (2018) study showed a misconception that adding the same number to both the numerator and denominator results in equivalent fractions. Lamon (2020) points out that fraction instruction has traditionally focused on only one interpretation of fractions, that of part-whole comparisons, that is presented in a context that allows for whole number reasoning, after which the algorithms for symbolic operation are introduced. Gee (2014) argues that classroom teaching tends to be assumed as focused only on textbook definitions of mathematical terms and procedures. For instance, defining equivalent fractions as two or more fractions that have different numerators and denominators but result in the same quantity after simplification, and unwittingly encouraging ordering of equivalent fractions by using the idea of 'multiplicative property of one', which I exemplify in the next section. However, geometric models offer the contexts to understand equivalent fractions (Lee \& Lee, 2020). For learners, focusing on symbolic representation of, for example, $\frac{2}{2}$ as 'two out of two' does not convey the meaning that this is 2 halves which is equivalent to, for example, four quarters, until a geometric (area) model is used (Figure 1).

Most preferably, instead, treatment of equivalent fractions using concrete models such as fraction bars to compare, for example, thirds and sixths and see that $\frac{2}{3}$ is exactly the same as $\frac{4}{6}$ provides meaningful learning of equivalent fractions. This is what is happening in most classrooms these days: teachers tend to focus on the textbook and thus ignore the value in eliciting learners' ideas in discussions claiming that they are wasting time. In this regard, despite that Lortie's (1975) work dates decades ago, little has changed in the teachers' daily struggles in the classroom, particularly more so for early career teachers.

\section{Exemplification of dialogic teaching of equivalent fractions}

Meaningful learning of fraction equivalence includes having an integrated knowledge, which can be displayed and articulated by means of the following five attributes:

1. A fraction represents a quantity being measured in relation to a referent unit (emphasis mine).

2. A fraction quantity can be represented using manipulatives or pictorially by partitioning (emphasis mine) area, collection or number-line models.

3. Equivalent fractions can be constructed from manipulatives or pictorial representations by repartitioning or chunking (emphasis mine).

4. Equivalent fractions can be constructed using symbolic notation.

5. A fraction quantity is a member of an equivalence class in which all fraction numerals represent the same quantity (Wong, 2010, p. 674).

\begin{tabular}{|l|l|l|}
\hline & & $\begin{array}{l}\text { 1. Shade in } \frac{2}{2} \text { of the shape, alongside. } \\
\text { 2. Can you think of another name for } \\
\text { the fraction shaded? }\end{array}$ \\
\end{tabular}

FIGURE 1: Different fractions that name the same whole (Adapted from the Trends in Mathematics and Science Study). 
Physical quantity, that is, the size or amount of a physical characteristic of an object, can be measured. For example, physical quantities encountered by young learners are: length, perimeter, area, volume, mass, etc. However, determining whether an answer about a physical quantity of an object, arrived at by using a calculator or paper-and-pencil method, is reasonable requires estimation ability. Estimation is the mental process of arriving at an approximate measurement without the aid of measuring instruments.

This then requires a learner to make a judgement of the size of a physical quantity relative to some specified unit. The notions of referent unit, partitioning, and chunking are at the core of the fractions domain in primary mathematics education, particularly in estimation. However, the question becomes, what do they mean? In what follows I define them in turn, paying particular focus to partitioning. The other two terms are merely defined for the purpose of completion; they are not a feature in the analysis.

A referent unit is a non-standard or standard unit that can be used to estimate a quantity. For example, if area is to be measured a two-dimensional unit like a playing card can be used as a referent unit or if the length of a pencil is to be measured matchsticks can be used as referent unit. Thus, the choice of an appropriate unit for measurement is a mathematical skill that is fundamental in learning to measure.

Partitioning means engaging in an intuitive activity that generates quantity to build knowledge about fair sharing. For example, in determining an equivalent fraction for $\frac{289}{24}$, we can break up 289 into parts that are easy to divide (e.g. division by 24 ) as displayed in Figure 2. The term chunking, in relation to fractions, refers to dividing a larger number that cannot be divided mentally, by repeated subtraction of the divisor and multiples of the divisor. For example, finding the answer to $\frac{155}{5}$ involves using numbers that are easy to multiply.

The teaching approach adopted by teachers in relation to equivalence may manifest itself in learners' work. Kerslake (1986) and Cramer and Henry (2002) found that learners in the Intermediate Phase predominantly favour circle models over geometric and linear models in representing fractions.

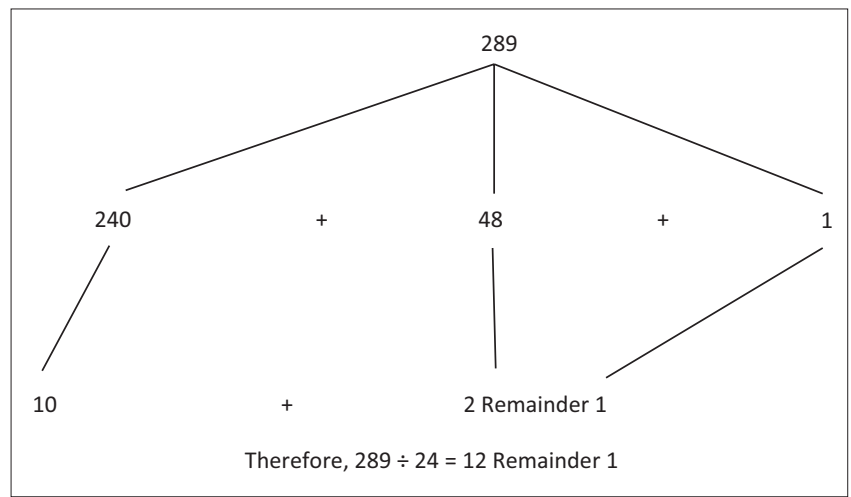

FIGURE 2: Division with partitioning.
They also found that some learners hold misconceptions when explaining equivalence. For example, learners reasoned that $\frac{4}{6}$ is double $\frac{2}{3}$. Teaching episodes should emphasise that although the fractions being pictured are different, each shows that the same portion of the region is shaded. That is, fractions that have the same value even though they may look different are identified as equivalent fractions. Therefore, equivalent fractions are fractions that are equal in value or size.

Figure 3 is designed to describe how dialogic teaching of equivalent fractions will look in a Grade 4 class. Since the objective here is to create opportunities for learners to make meaning for themselves, a paper-folding activity will lead to them 'discovering' a general rule (i.e. a generalisation) that the sequence of fractions arises from multiplying $\frac{1}{2}$ with the number of regions created by the folding. In this activity, learners are provided with a rectangular region, half of which is shaded. Then, they are directed to fold it into two congruent parts as shown in Figure $3^{5}$ by the broken line through the region. This procedure is repeated over and over again, scaffolding learners' development of the concept of equivalent fractions using prompts each time (suggested answers in brackets). This procedure is consistent with Lannin, Ellis, Elliott and Zbiek's (2011) recommendation that teachers need to encourage their learners to connect examples, extend their ideas to new situations, and identify commonality across cases or to extend commonality beyond the domain of the original pattern from primary mathematics classes.

An alternative generalisation approach, provided by Putra and Winsløw (2018), would be using the 'multiplicative property of one':

$\frac{\mathrm{a}}{\mathrm{b}}=\frac{\mathrm{a}}{\mathrm{b}} \times 1=\frac{\mathrm{a}}{\mathrm{b}} \times \frac{1}{1}=\frac{a \times n}{b \times n}$

For example, for nd $a=1$ and $b=2$ :

$\frac{1}{2}=\frac{1}{2} \times \frac{1}{1}=\frac{1}{2} \times \frac{2}{2}=\frac{2}{4}=\frac{1}{2} \times \frac{3}{3}=\frac{3}{6}=\frac{1}{2} \times \frac{4}{4}=\frac{4}{8}$

However, the 'paper-folding' activity is a superior method in promoting meaningful learning through dialogic teaching. As Gattegno (2010) points out - using the idea of identity element for multiplication, as shown above - we can see that equivalence is concerned with a wider relationship where it is possible to replace one item by another. Further, he argues, equivalence is a domain of primary mathematics that constitutes the most comprehensive relationship 'and therefore the most useful' (p. 129). He exemplifies this claim in everyday life, pointing out that to say that 'He is on my left' is equivalent to saying that 'I am on his right' and 'I am taller than her' is equivalent to 'She is shorter than me'.

5.Figure 3 is a synthesis of ideas and work adapted from Marmur, Yan and Zazkis (2020) and Pedersen and Bjerre (2021). 


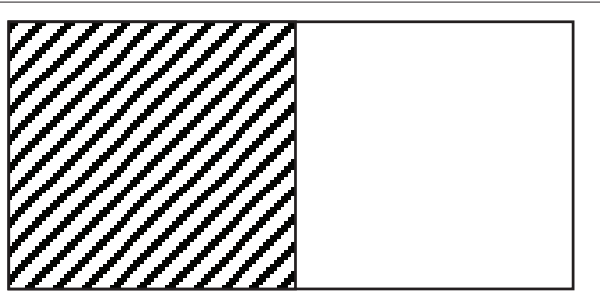

1. What fraction is pictured here? $(1 / 2)$

2. How do you know that,Nosipho?

(In the rectangle partitioned into

two parts, only 1 part is shaded)

3. Sipho, do you agree with her? If so, why?

4. Shaded parts? (1)

5. Parts in total? (2)

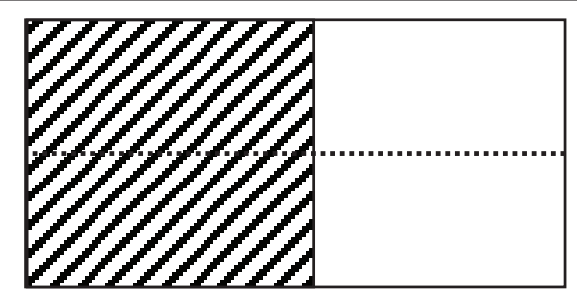

1. What fraction will be pictured when the paper is unfolded? $2 / 4$

2. Shaded parts? (2)

3. Parts in total? (4)

4. Will more of the paper be shaded than was shaded before the folding? (No)

5. Why do you think so? (The size of the rectangle hasn't changed)

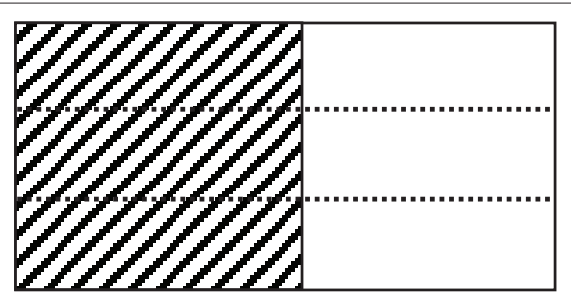

1. What fraction will be pictured when the paper is unfolded? $3 / 6$,

2. Shaded parts? (3)

3. Parts in total? (6)

4. How could you explain what $50 / 100$

means? (Take 50 shaded parts and

double the parts in total, 50/100).

5. Can you think of any

[nth] fraction with half

the shape shaded? $(n / 2 n)$.

FIGURE 3: Development of a general statement about equivalent fractions.

\section{Theoretical framework}

The study reported in this article employed Alexander's (2020) notion of 'dialogic teaching' as a theoretical basis guiding formulation of research questions, methodology, and discussion of results. The central premise of this notion is that encouraging learners to share their thinking enables teachers to diagnose learners' misconceptions, devise tasks to dispel misconceptions, and assess learners' progress. Dialogic teaching is based on the proposition that classroom talk must be positioned firmly at the heart of the learner's learning and the teacher's practice. In addition, dialogic teaching emphasises the value of the teacher's guiding role in the development of learners' mathematical understanding given that primary school children often lack the necessary skills to manage their joint activity (Mercer \& Sams, 2006). Thus, the concept of dialogic teaching is relevant for this study in that its foundational idea is that primary school learners need 'guided construction of knowledge' as they participate in group activities that offer valuable opportunities for them to construct solutions for themselves through talk, which would not be found in whole-class instruction (Mercer \& Sams, 2006). Put another way, it is through teacher's talk that learners' talk is prompted.

Dialogic teaching combines four repertoires (and their subcategories): talk for everyday life, learning talk, teaching talk, and classroom organisation. These repertoires are used flexibly, on the basis of fitness for purpose. Additional to these repertoires, Alexander (2020) proposes five principles: collective (the classroom is a site of joint learning and enquiry), reciprocal (participants listen to each other, share ideas and consider alternative viewpoints), supportive (participants feel able to express ideas freely, without risk of embarrassment over 'wrong' answers, and they help each other to reach common understandings), cumulative (participants build on their own and each other's contributions and chain them into coherent lines of thinking and understanding), and purposeful (classroom talk, although open and dialogic, is structured with specific learning goals in view). Although Alexander's notion of dialogic teaching encompasses a broad repertoire of strategies and techniques, only the following will be considered for the purpose of this study:

- structuring of questions so as to provoke thoughtful responses

- individual teacher-learner exchanges are coherent, connected lines of enquiry that do not leave learners stranded.

In this article, I analysed Nox's teaching of equivalent fractions. The purpose of this article was neither to praise nor be critical of her pedagogy. Similarly, I did not intend to advocate or critique the use of dialogic teaching approach in equivalent fractions. Rather, the purpose of this article was to present an analysis of her instruction itself and thus offer a more precise description of what occurred in her classroom. A second purpose was to discuss why Nox chose to teach equivalent fractions in the way that she did.

\section{The research questions}

Using Alexander's (2020) perspectives as an explanatory framework in relation to dialogic teaching, the following specific research questions were posed to guide the study:

- How does Nox structure her questions to learners so as to provoke thoughtful responses in the learning and teaching of equivalent fractions?

- Why did Nox teach equivalent fractions in the way she did?

\section{Methods and design Study design}

The study reported in this article is part of a larger project looking at the classroom practices and professional development of an early career primary mathematics teacher. A qualitative case study design was adopted. In a qualitative inquiry the researcher studies meanings constructed by participants on a phenomenon in their natural setting (Denzin \& Lincoln, 2011). Observational data as well as follow-up semi-structured interview data were collected in the spirit of naturalistic inquiry (Lincoln \& Guba, 1985). The 
use of multiple data collection methods not only strengthens the validity of the findings (Howitt \& Cramer, 2005) but also reflects an attempt to secure an in-depth understanding of Nox's instructional patterns of talk, and is of importance particularly for an individual researcher (Patton, 2002).

\section{Ethical considerations}

Ethical approval was granted by the Ethics in Research Committee of the University of KwaZulu-Natal.

This research is part of a larger project designed to follow the experiences an early career teacher in the pedagogy of mathematics and ethical approval was granted by the Ethics in Research Committee of at a university in south-eastern South Africa withaprotocolnumberHSSREC /00001902/2020. Informed consent was obtained from all participants.

\section{Participants and context}

The empirical research reported in the present study involved data from a main project designed to follow the professional development of an early career teacher, Nox (pseudonym), in a Grade 4 class (nine- and ten-year-olds) who were conveniently sampled to participate in the study. Nox had a four-year professional teaching degree in primary mathematics. At the time of the study (2020), she had 2 years of teaching experience. She taught at a rural combined primary school in the Eastern Cape, South Africa, which I shall call Fundisanani. The school is situated in a village (rural area) and serves learners from a low socio-economic background, in an isiXhosa-speaking African community with high absenteeism rate for both learners and teachers. Like most rural schools in the area, it was under-resourced, had no laboratory or media centre, nor sports field. The names of all participants and schools have been changed to preserve anonymity.

The context of the study was kept as normal as possible, in three ways. First, Nox was observed teaching equivalent fractions in her Grade 4 classroom under the general topic 'Fractions'. Second, the lessons on equivalent fractions that were audio recorded were selected from the typical, prescribed primary school mathematics curriculum. Third, the researcher was a spectator observer (Patton, 2015) who gathered data from Nox in her natural classroom setting. The class enrolment was 48 learners of multiple ability levels. The mathematics period in the class was approximately one hour long, five days per week. A typical lesson often began with the learners engaging in mental calculation of whole numbers including estimation, building up and breaking down numbers, rounding off and compensating and doubling and halving, all to be completed in 10 minutes. The curriculum was organised around units on general mathematical topics such as: numbers, operations and relationships, patterns, functions and algebra, geometry, measurement, and data handling.

\section{Data collection and procedure}

Qualitative data were collected by employing two methods: classroom observation and semi-structured interviews. The purpose of the observation was to understand how they orchestrate dialogic strategies in their context-specific settings. As already mentioned, Nox was observed in her natural setting (i.e. the classroom). Data were audio recorded and transcribed verbatim. An audio recorder was strapped to Nox's waist to capture all the teaching proceedings including interactions in group work and any non-verbal communication. Given that the purpose of the observation was to understand how Nox orchestrated dialogic strategies in her contextspecific settings - that is, I was particularly interested in the teacher talk - I concentrated on recording solely Nox. Another reason for recording only her talk was to minimise interference with learners' behaviour so that their talk would be natural.

The classroom observation protocol was used to answer the first two research questions by documenting what Nox said in telling her story on equivalence. The tool also included background information, contextual background and activities, and 10 items on a four-point Likert-type scale. The items are on a continuum ranging from 'Never occurred' to 'Very descriptive'. In this section, items on the left in the continuum of the scale are generally more 'traditional' and those on the right generally reflect more dialogic teaching. These items provided the operational definitions for dialogic teaching typology. The typology was meant to capture, in retrospect, the observer's overall interpretation of the teaching approach observed in the classroom. The observation lasted 40 minutes.

Additionally, Nox was interviewed after the lesson observations to establish reasons for the observed teaching sequences. The interview also helped in triangulation of observation data with interview data. Sample questions on the interview schedule included 'Why do you ask learners to clarify their homework activities?', 'Describe your teaching of equivalent fractions', and 'Why do you teach equivalent fractions the way you did in the lesson?'. The interview lasted for 45 minutes.

\section{Analysis}

The purpose of the proposed study is to investigate how practising Grade 4 teachers use dialogic teaching to orchestrate classroom interaction in the context of equivalent fractions. The data were subjected to thematic analysis since this method offers 'a more accessible form of analysis, particularly for those early in a qualitative research career' (Braun \& Clarke, 2006, p. 81). Further, as Fielden, Sillence and Little (2011) indicate, this analysis method allows the researcher to explore the individual experiences of participants and the meanings they attribute to them. The analysis took into account the notion that data analysis should end when it yields no further information. This analytical approach was adopted on the basis that 'failure to reach saturation has an impact on the quality of the research conducted' (Fusch \& Ness, 2015, p. 1408). Reaching this point added to the trustworthiness of the results.

In particular, transcribed excerpts from episodes of audio recorded lessons of Nox's dialogic strategies were used to 
examine how she drew on dialogic teaching principles proposed by Alexander (2004) to make understanding of equivalent fractions available on the social plane, at their different schools. That is, Alexander's predetermined categories were used to assess how the participating teachers make opportunities for understanding equivalent fractions available for learners in their classrooms, particularly probing learners' answers with the 'Why do you think that?' question. Nox's talk, rather than learner-learner interactions, was analysed. It is worth emphasising that the microphone was sensitive enough to record learner-learner talk, as well.

On the whole, to investigate the two research questions underpinning this study, the analysis mainly focused on the identification of interactions using Alexander's (2020) lens to make conclusions on the orchestration of dialogic teaching by Nox, noting how she handled learners' ideas from the lens of dialogic teaching. In analysing the data obtained from the two sources-classroom observation and interviewattention was paid to whether Nox's classroom talk was truly dialogic by examining whether a question posed gave rise to a new question and the extent to which her teaching required learners to think rather than merely report someone else's thinking (Alexander, 2020; Bakhtin, 2010; Nystrand, 1997).

The observation transcript was also coded by a doctoral student whose work was in the area of dialogic teaching. A very high inter-rater reliability - where researchers are expected to independently identify the same codes in a transcript and the codings compared for agreements - was reached (Creswell, 2012). In addition to verbatim transcription of the data and the use of multiple data collection methods, a copy interview transcript and a draft of the interpreted results were sent to Nox for review. She corrected two errors and provided additional information. All these measures were undertaken to improve the trustworthiness of the interpretations (Creswell, 2012).

Collection of classroom observation data ceased when saturation was reached. Data saturation is a methodological principle in qualitative research that is commonly taken to indicate that, on the basis of the data that have been analysed hitherto, further data analysis is unnecessary (Fusch \& Ness, 2015). It refers to the point in the research process when no new information is discovered in data analysis, and this redundancy signals to researchers that data collection may cease. Saturation, more broadly construed, means that a researcher can be reasonably assured that further data analysis did not necessarily add anything to the overall story of the participant (Saunders et al., 2018).

\section{Results}

To provide answers to the first research question meant analysing ways Nox structured her classroom talk, especially her questions. This was also a way to search for evidence of dialogic teaching of equivalent fractions as her lesson unfolded. As already mentioned, the analysis focused solely on Nox's talk structure given the consensus that, as a teacher, she was the single most important school variable influencing learner achievement. The question remains whether her instructional practice showed traces of the principles of dialogic teaching the lens through which the data in this study was analysed that would have enhanced learning of equivalent fractions.

To highlight the principles, we consider Nox's lesson on equivalent fractions in her Grade 4 class. Primary school teachers are encouraged to engage learners in mental work prior to beginning a mathematics lesson. However, interactions in this respect, though interesting, were not analysed as they fell outside the scope of the study. The results are presented in terms of the two research questions.

\section{Description of Nox's lessons}

The first research question was formulated to assess how Nox probed her learners to say more about their responses. In the classroom, Nox was standing in the front of the learners facing the chalkboard. The learners were sitting at desks arranged in rows. She wrote the topic 'Equivalent fractions' on the chalkboard. The excerpt below shows how Nox introduced her lesson, proceeding from the previous lesson's activity; perhaps some patterns of dialogic teaching could be observed. Nox checked learners' thinking on a previous activity involving different ways of representing fractions (using fractions to describe pictures). Noticeable was that the work was void of context; I expected a word problem, at least.

Table 1 served two purposes. First, it provided the context of the classroom environment in which Nox worked. Learners took some time to settle down and Nox had to talk at the top of her voice to address the behaviour. The learners were responding in chorus form (Turn 6) until she decided to point at individual learners when seeking a response (Turn 12). Second, although the topic handled in this excerpt was representations of fractions, the excerpt captures Nox's commitment to collecting learners' ideas. In Turns 5 to 12 , Nox collected

\begin{tabular}{|c|c|c|}
\hline Turn & Speaker & Transcription \\
\hline 1 & Nox & $\begin{array}{l}\text { Ok ... [with a loud voice trying to quiet down the } \\
\text { learners and get their attention], good morning } \\
\text { Grade } 4 \text { ! }\end{array}$ \\
\hline 2 & Class [Chorus] & Good morning, Mam! \\
\hline 3 & Nox & How are you? \\
\hline 4 & Class [Chorus] & We are fine. Thank you, teacher and you? \\
\hline 5 & Nox & $\begin{array}{l}\text { I am fine. You can sit down. Ok, the last time we were } \\
\text { dealing with ... [inaudible], isn't it? Let us mark the } \\
\text { homework. Who can write two-fifths in symbols? }\end{array}$ \\
\hline 6 & Class Chorus] & Me, me, me, ... \\
\hline 7 & Nox & Yes, Xola! \\
\hline 8 & L1 & [Moving to the board and writes] $\frac{2}{5}$ \\
\hline 9 & Nox & $\begin{array}{l}\text { Hmmm ... Let's see [looking at the fraction diagram on } \\
\text { the wall]. How do you know it's correct? }\end{array}$ \\
\hline 10 & L1 & Ahhh ... Mam. I take ... hmm ... two things in 5 things. \\
\hline 11 & Nox & $\begin{array}{l}\text { Oh, I see. Class is he correct? [interruption by knock at } \\
\text { the door] Yes, come in, Nonhle [another learner arriving } \\
10 \text { minutes into the class]. Yes, Nosipho, tell us! }\end{array}$ \\
\hline 12 & L2 & Yes, Xola ... have the right things. \\
\hline 13 & Nox & Good. Now, let's go to the second problem. \\
\hline
\end{tabular}


learners' ideas and refrained from providing immediate evaluation of those ideas or responses at least from two learners before evaluating the answer and thus closing the talk with, 'Good'. This suggested that Nox elicited learners' answers or ideas through questions, which probed their point of view.

Moving now to the gist of the lesson - that is, the focus on how she orchestrated the interactions with her learners to tell the story of equivalence - we find Nox trying to engage her learners in more talk on the topic, equivalent fractions (see Table 2). She used the fraction wall to introduce her learners to the concept of equivalent fractions (e.g. the idea of multiplication of numerator and denominator by the same number results in the same numerical value, except 0 ). She asked them to follow the line separating the two halves on the strip to see that $\frac{1}{2}$ is the same as $\frac{2}{4}, \frac{4}{8}$ and $\frac{5}{10}$.

As an early career teacher, Nox deferred the same question to other learners for their ideas, using phrases such as 'Sipho thinks that half is the same as two quarters, do you agree with him?' Put another way, I sought to examine whether Nox chained learners' responses to follow coherent lines of thinking about the same idea to enhance meaningful learning of equivalent fractions. Her phrasing of the question suggested that she wanted to provoke thoughtful responses and see interanimation of ideas in her classroom talk. Seemingly convinced that the learning of equivalent fraction had taken place, Nox proceeded to seek a general rule to check if two fractions are indeed equivalent, as shown in Turn 16 (see Table 3). Nox's intention to introduce abstraction here is commendable and consistent with Lannin et al.'s (2011) argument that generalising is a practice that needs to permeate primary mathematics classes and beyond. She

\begin{tabular}{|c|c|c|}
\hline Turn & Speaker & Transcription \\
\hline 1 & Nox & $\begin{array}{l}\text { Using the fraction wall, in how many different ways can make } \\
\text { a } \frac{1}{2} \text { ? Yes, Pat! }\end{array}$ \\
\hline 2 & L3 & There's 5, Mam! \\
\hline 3 & Nox & Why do you say 5 ? Can you mention just one? \\
\hline 4 & L3 & $\frac{2}{4}[$ Nox recorded the answer on the chalkboard]. \\
\hline 5 & Nox & Ok. How do you know that? \\
\hline 6 & L3 & $\begin{array}{l}\text { You see, hmmm ... if you cut the ... ilento [isiXhosa for 'thing', } \\
\text { the paper strip] to } 4 \text { pieces, they are the same like that } \\
\text { [pointing] that half. So, we can say that } \frac{1}{2} \text { is equal to } \frac{2}{4} \text {. } \\
\text { [Collective clapping of hands]. }\end{array}$ \\
\hline 7 & L4 & $\frac{4}{9}$ \\
\hline 8 & Nox & No [Seeking more ideas]. What do you think, Lunwabo? \\
\hline 9 & L5 & Mam, $\frac{1}{2}$ is also equal to $\frac{4}{8}$ ? \\
\hline 10 & Nox & $\begin{array}{l}\frac{1}{2} \text { is also equal to } \frac{4}{8} \text { ? [repeating the learner's answer]. Why } \\
\text { do you say that? }\end{array}$ \\
\hline 11 & L5 & $\begin{array}{l}\text { If we look at the two shades [pointing at } 2 \text { nd and } 4 \text { th rows], the } \\
\text { one half and the four eights ... they take the same space [area]. }\end{array}$ \\
\hline 12 & Nox & Class, do you see what they are saying? \\
\hline 13 & $\begin{array}{l}\text { Class } \\
\text { [Chorus] } \\
\end{array}$ & Yes, Mam! \\
\hline
\end{tabular}

seems to believe that her learners have developed an understanding of equivalent fractions beyond the concrete level in which they used the fraction wall as a referent. However, she seems to have rushed her learners without having given them opportunities to explore with a finite number of cases involving equivalent fractions. Evidence for this claim is provided by Turn 20, where Learner 6 asks 'What is $a$ ? ... Yeah, what is the use ... [of the] letters?' Learner 8 expressly voices the conclusion 'It's looking difficult'. In Turn 21, Nox seems to return to numerical fractions $\frac{2}{3}$ and $\frac{4}{6}$. These learners' statements and questions seem to break her attempt to sustain her probing to sustain the talk, as envisaged in the principles of dialogic teaching.

What is happening in the extract above is that Nox seems to have involved many different learners in seeking an understanding of the rule. However, a close examination reveals that the voices she sought were on different aspects of the generalisation rule (i.e. $\frac{\mathrm{a}}{\mathrm{b}}=\frac{\mathrm{a}}{\mathrm{b}} \times 1=\frac{\mathrm{a}}{\mathrm{b}} \times \frac{1}{1}=\frac{a \times n}{b \times n}$ ); learners' ideas were collected only to confirm understanding rather than seek to chain these ideas into coherent lines of thinking about the same idea that has been made available on the social plane at a particular time of the exchange. Evidence for

TABLE 3: Learners show difficulty with making a generalisation.

\begin{tabular}{|c|c|c|}
\hline Turn & Speaker & Transcription \\
\hline 14 & Nox & $\begin{array}{l}\text { Now, we need to find a rule for working out equivalent fractions? } \\
\text { Alipheli, what can we do? }\end{array}$ \\
\hline 15 & L7 & Eish, Eish, Mam, kumnyama [isiXhosa for 'I have no clue'] \\
\hline 16 & Nox & $\begin{array}{l}\text { If } \frac{\mathrm{a}}{\mathrm{b}}=\frac{\mathrm{c}}{\mathrm{d}} \text { then } a \times d=b \times c \text { [Writing on the chalkboard]. You can } \\
\text { remember this rule to check equivalent fraction without looking } \\
\text { at the wall. [Interruption by L2] }\end{array}$ \\
\hline 17 & L2 & I don't see this thing, Mam. \\
\hline 18 & L7 & Me, too. \\
\hline 19 & Nox & $\begin{array}{l}\text { We can say that ... Hmmm ... two fractions are equivalent or equal if } \\
\text { the product of the numerator }(\alpha) \text { of the first fraction and the } \\
\text { denominator }(d) \text { of the other fraction ... You see them [Pointing at the } \\
\text { letters in the proportion] ... if their product is equal to the product of } \\
\text { the denominator }(b) \text { of the first fraction and the numerator }(c) \text { of the } \\
\text { other fraction [Pointing at the letters in the proportion]. Ok? ... } \\
\text { Remember that product means multiplication. Any question? }\end{array}$ \\
\hline 20 & L6 & Yes, what is a? Yeah, what is the use ... [of the] letters? \\
\hline 21 & Nox & $\begin{array}{l}\text { Look, if } \frac{2}{3} \text { is really equal to } \frac{4}{6} \text {, then you must check if } 2 \times 6=3 \\
\times 4 \text {. Is this true? }\end{array}$ \\
\hline 22 & L3 & Yes, Mam, ... Hmmm ... I find 12 is 12. \\
\hline 23 & Nox & $\begin{array}{l}\text { Good, if you see that the two sides are equal, it means that the } \\
\text { fractions are equivalent. If they are not, the two sides will not be } \\
\text { equal. Let's look at this! } \\
\text { Is it true that } \frac{2}{3}=\frac{3}{4} \text { ? Yeah, Mncedisi! }\end{array}$ \\
\hline 24 & L7 & $\begin{array}{l}2 \times 4 \text { ayifani [isiXhosa for 'is not the same'] no [isiXhosa for 'as'] } \\
3 \times 3 \text {. Jonga [isiXhosa for 'Look'], } 8 \text { is not } 9 \text {. }\end{array}$ \\
\hline 25 & Nox & What do you say, wena [isiXhosa for 'you'] \\
\hline 26 & L9 & Oh, yeah, ndyabona ngokhu [isiXhosa for 'I understand it, now']. \\
\hline 27 & L8 & It's looking difficult. \\
\hline 28 & Nox & $\begin{array}{l}\text { Try to practise using your own examples. Hmmm ... you'll } \\
\text { understand, Andithi? [isiXhosa for 'Isn't so']. }\end{array}$ \\
\hline 29 & $\begin{array}{l}\text { Class } \\
\text { [Chorus] }\end{array}$ & Yes ... \\
\hline 30 & Nox & $\begin{array}{l}\text { Do these exercises in your Bluebook! [Calling out the page } \\
\text { number of the practice exercises in the workbook (commonly } \\
\text { referred to as the "Bluebook" and used as a textbook in South } \\
\text { Africa from reception year to Grade 6)]. }\end{array}$ \\
\hline
\end{tabular}


this claim is found in Turn 30 as she wraps up her lesson by fixing her focus on giving learners some 'exercises' to do in their Bluebook. The dialogic exchanges ended abruptly as she leaves it to learners to pursue the concept of generalising equivalent fractions at 'home'.

Although Nox asked a question that appeared 'dialogic' in that it contained the 'why' cue, she did so from the perspective of a teacher with an authoritative stance (as she sought to maintain school mathematics position; pressing for the three principles of dialogic teaching was not explicit in the lessons observed). This need not necessarily be construed as an indictment on Nox's practice. She had to teach her learners in an environment that was not conducive to the principles of dialogic teaching; this could have limited her enactment of dialogic teaching in the classroom. Learners' responses to such a question functioned to respond to mathematics content because Nox utilised cues such as 'Why ...' and 'How do you ...' only to understand how closely the learners' responses aligned with some school-sanctioned or predetermined disciplinary stance.

Figure 4 is a conceptual diagram that depicts Nox's arrangement and relationships of the key ideas in telling the story of equivalent fractions for her Grade 4 class as conceived in her mind (depicted in the conceptual diagram). The basis for labelling it as 'conceived in her mind' arose from her agreement with it after I presented it to her during member checking to enhance the trustworthiness of the findings. That is, this diagram was discussed with Nox to seek her agreement with the way I saw her teaching of the ideas encapsulated in equivalence. Modifications were made; for example, because there was no episode in which she wrapped up the lesson to remind her learners of key ideas she wanted them to 'take home', the diagram only displays the introduction and the teaching of the content. Thus, the conceptual diagram summarises the story that developed in Nox's lessons that were observed.

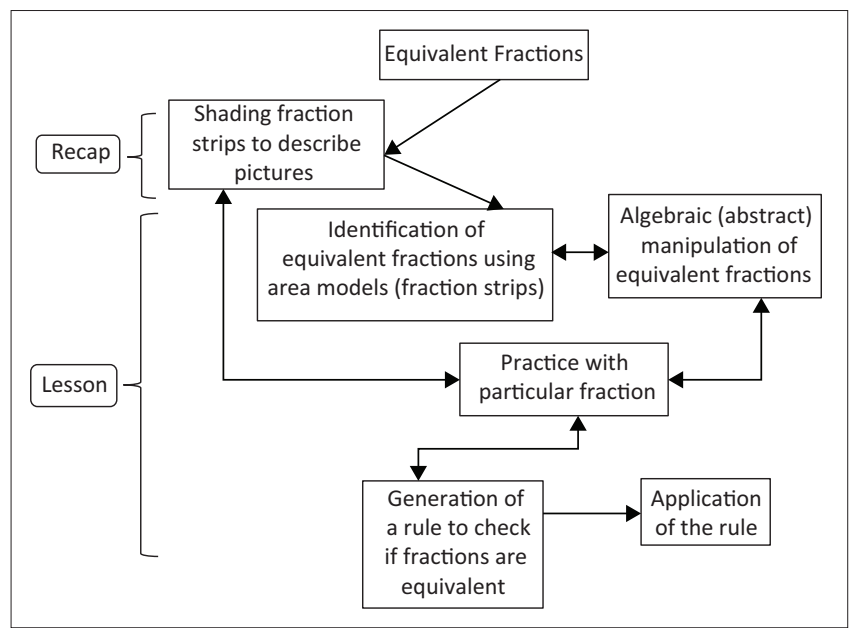

FIGURE 4: Nox's conceptual framework in teaching equivalent fractions.
Although Nox mobilised learners' ideas, she did not anchor her questions and comments in learners' contributions. In other words, despite utilising cues such as 'why' and 'do you believe', she only truly cared about how closely the learners' response aligned with disciplinary knowledge. This talk structure does not, in any way visible to an analyst, embody any 'scaffolding' intended for meaningful meaning of equivalent fractions. Nox engaged her learners in a mathematical activity of talking about equivalent fractions. Accordingly, she showed part of mathematical practice in her use of the 'why' cues to seek confirmation or further development of an idea.

In her 29 turns of talk, Nox asked a total of 16 questions that could be designated as 'closed' exchanges. During the dialogue, learner participation can be characterised as providing 'correct' answers intended to demonstrate to Nox that her learners were indeed recalling the knowledge as transmitted in the previous lesson. Nox implicitly indicated that a learner's answer was incorrect by not recording it on the chalkboard or by ignoring it and continuing to ask other learners for the 'answer' (Turn 4 and Turn 7 of the second excerpt). Worthy to mention here is that including other episodes would have served no purpose in that data saturation was reached at this point. That is, further analysis beyond this point did not yield new results. Thus, further coding of observational data was no longer feasible.

\section{Why did Nox teach equivalence in the way that she did?}

Dialogic teaching is an approach whose success is affected by contextual factors. Hence, it was necessary to conduct an interview to understand why Nox approached the teaching of equivalent fractions the way she did. School factors such as the routine of holding assembly in the morning prior to commencement of lessons, the movement of learners as they change classes, the pressure to complete the curriculum, and late arrival played a role in her teaching of equivalent fractions. Although cross-national research studies have shown that a significant number of teachers exit their initial (preservice) teacher preparation programmes with inadequate knowledge of mathematics (eds. Tatto, Rodriguez, Smith, \& Reckase, 2018), this factor was not investigated.

Asked to reflect on her teaching in the lesson, she pointed out that collecting learners' ideas 'makes the lesson messy; these kids get involved in arguments'. Interested to understand better what she meant by 'arguments', I probed (see Table 4). Her response was: 'They trying to outshine each other rather than answering the question'. This response pointed to the breakdown in talks meant to make the learning of equivalent fractions a cumulative process. The interpretation arising from these statements are that Nox felt that allowing learners to engage in interactions among themselves is a recipe for chaos in the classroom as they begin to compete in ways that do not take their learning of equivalent fractions forward. This finding seems to corroborate Nathan and Knuth's (2003) finding that although learner-learner dialogue increases participation, this takes place at the expense of mathematical precision. 
TABLE 4: Nox's reflections on her lessons.

\begin{tabular}{ll}
\hline TABLE 4: Nox's reflections on her lessons. \\
\hline Researcher & $\begin{array}{l}\text { Reflections } \\
\text { Why do you ask the 'why' questions and make no further attempt } \\
\text { to build on it to sustain learners' participation? }\end{array}$ \\
Nox & $\begin{array}{l}\text { Hmmm ... I have to remember that I have a duty to complete the } \\
\text { curriculum ... I wish I has sufficient time. But, I have other subjects } \\
\text { to move to. }\end{array}$ \\
Researcher & $\begin{array}{l}\text { I hear you. I hear you, well. But, don't you think that it's better to } \\
\text { not finish the curriculum but have meaningful learning of } \\
\text { equivalent fractions? }\end{array}$ \\
Nox & $\begin{array}{l}\text { Yeah, yes, honestly that will be a great thing to do. But, if I do it, } \\
\text { yeah ... I'll [be] behind the schedule. I'll be called to the principal's } \\
\text { office to explain. No one will listen to my reasons. Hmmm no time } \\
\text { for consolidation of work. }\end{array}$ \\
Researcher & $\begin{array}{l}\text { What do you mean by 'consolidation of work?' } \\
\text { Nox }\end{array}$ \\
$\begin{array}{l}\text { There's too much content. Eish, yo, yo, yo. Don't get me wrong. I } \\
\text { enjoy my maths but the learners only know the surface of maths .... } \\
\text { to pass the grade. }\end{array}$ \\
\hline
\end{tabular}

During the interview, Nox also raised time as a scarce resource, as captured in the following excerpt.

As can be found in pedagogical exchanges in most classrooms the world over, Nox clearly indicated that time limited her disposition to engage in dialogic teaching because she considered the curriculum too heavy. This suggestion brings to the fore the need for mentoring programmes or an improvement in inductive programmes for early career teachers so that they can enact reformoriented teaching such as dialogic teaching. Most probably time can be found by looking into the activities that seemed to consume teaching time. For instance, Nox's lesson was scheduled to take 40 minutes yet half of it was taken by the morning assembly lasting beyond the allocated time on the school's timetable. There is truth in what Nox is saying: she is in a daily grind in which she is facing challenges that come with being an early career teacher (Lortie, 1975). Put another way, she is in a routine that Jackson (2004) refers to as 'the daily grind' of teaching in a primary classroom - where 30 or more people spend several hours each day literally side by side - and things do not always go according to expectations.

Another limiting factor was learners' late arrival which disturbs the flow of teaching. Nox has had to recap to bring the late learners trickling into the classroom up to speed with the ideas already entertained in the class. Her efforts support the notion that teachers generally want all learners to understand the contents of their lessons (Van de Walle, Bay-Williams, Lovin, \& Karp, 2013). Her work is made more challenging by the fact that she was teaching in a rural school with very limited resources that can be used to mitigate her challenges (e.g. technology with the facility to draw the attention and interest of learners as they 'see' and 'do' the shading of area models involving equivalent fractions).

\section{Discussion}

The purpose of this study was to explore possible instances of dialogic teaching in Nox's mathematics classroom. In particular, the exploration involved examining how she uses dialogic strategies to tell the story of equivalent fractions, that is, how different ratios can have the same value. To remind the reader, dialogical teaching, in a weaker sense, refers to classroom interactions in which multiple speakers take extended turns which take account of others' ideas (Scott, Mortimer, \& Aguiar, 2006). The discussion of the results is organised in terms of the two research questions.

\section{Searching for thoughtful responses}

Teacher's questions in dialogic teaching approach are structured so as to provoke thoughtful responses, which refers to questions that provoke further questions to create a coherent line of enquiry in relation to equivalent fractions. Nox's interest in collecting learners' ideas was to give learners an opportunity to relate them to their existing knowledge, in this case knowledge of equivalent fractions. This practice was in fulfilment of Ausubel's (2012) argument that new knowledge should invoke links within the learner's cognitive structures (i.e. the knowledge that the learner organises in ways that can be used in new contexts). The results suggested, however, that Nox missed opportunities to exploit learners' responses to provoke further questions that sustained their participation. In other words, Nox-learner exchanges were disconnected in that she focused on completing the curriculum. She enacted the question-and-answer sequences, a practice whose sole purpose is to test retention of arbitrary items of given knowledge rather than to support the development of meaningful learning of equivalence. The testing of whether learners have retained the requisite knowledge is crucial for Nox in accounting about learner performance. Evidence for this claim is found in her interview utterances: 'I have to remember that I have a duty to complete the curriculum'.

In addition, Nox-learner exchanges were not, in Alexander's (2006) terms, 'chained into coherent lines of enquiry' (p. 32). That is, new concepts were not connected in any substantive manner to learners' ideas but were merely designed to be memorised, thus promoting the formation of, in Ausubel's (2012) terms, arbitrary relationships among ideas in the learners' minds. This was evident particularly in Nox's attempt to develop the general rule. In contrast to Putra and Winsløw's (2018) findings, Nox seemed not to have paid attention to learners' development of a meaningful understanding of how to make a generalisation, for example, when she referred to $\frac{a}{b}=\frac{c}{d}$ and why the rule works prior to applying it in their work with equivalent fractions. Taking the definition of thoughtful responses into account, it is reasonable to conclude that there was little evidence that Nox's lessons reflected traces of this dialogic principle in her teaching of equivalent fractions. Thus, observational evidence supported by her own words suggested that there was little evidence of meaningful learning of equivalent fractions, particularly the generalisation process. There were, however, other variables that were at work in her teaching approach. 


\section{Nox's teaching practice in terms of her environment}

Classroom observation of and interview with Nox provided insight into the contextual factors that influenced her teaching of equivalent fractions. The actual time spent observing Nox's lessons was not commensurate with that allotted in the timetable. The effect of this factor was corroborated in Nox's own words. During the interview, she highlighted that ideally she would like to see her learners make sense of equivalent fractions. In other words, she indicated that she would like to see her learners build on what has been said by the previous speaker to increase the coherence of the exchanges. However, such exchanges were few and far between, because 'if I do it, yeah ... I'll [be] behind the schedule'. The finding here is that she attributed her approach to the teaching of equivalent fractions to the limited time; the curriculum was congested to cover the prescribed content.

Nox pointed out that she had to resort to teaching methods that offer little in terms of meaningful learning of equivalent fractions. She acknowledged that learning equivalent fractions in arbitrary fashions undermines the connected nature of mathematics concepts. Interview results sustained the inference made in the observation data that Nox's teaching approach mimicked transmission teaching. However, what emerged from the interview was that Nox's choice of teaching approach was not made with reckless disregard for meaningful learning; school environmental circumstances contributed.

In sum, analysis of both classroom observation data and interview transcript call for teaching approaches that position learners' ideas at the centre of instruction in line with current reform initiatives in curriculum documents (Common Core State Standards Initiative [CCSSI], 2010; Department of Basic Education [DBE], 2011). Meaningful learning of equivalent fractions (at the Grade 4 level) is important because it is a topic needed for all mathematical operations (addition, subtraction, division, and multiplication). However, personal experiences supported by research, for example Davis and Maher (1997), suggest that the main objectives of teachers working from the 'transmission' model of instruction (i.e. question-answer and listen-tell routines) have been computational and definitional, rather than pursuits of meaningful learning. Teachers of young children (i.e. children in the Foundation Phase, namely reception year to Grade 3) are often trained to teach a wide range of subjects, which leaves little room to develop mathematical knowledge (Newton \& Newton, 2007). As a consequence, these teachers tend to avoid 'conversational risk' and instead focus on facts, routines, and right answers at the expense of pressing for understanding of the reasons underpinning these (Carlsen, 1991). In this regard, I recommend that initial teacher training programmes make dialogic teaching an explicit outcome in their course; or it will never be learned.

\section{Limitation of the study}

As is often the case in any research, one limitation should be borne in mind when interpreting the results of this study. Learner-learner interactions were not analysed. This was not designed to discount learners' voices; learners' talk is a crucial part of a pedagogical event. This limitation suggests an opportunity for further research. Future research may incorporate this component of classroom interactions to better understand how learners view the teaching approach adopted by early career teachers in equivalent fractions.

\section{Conclusion}

In this article, I described how the teaching approach adopted by the focal teacher, Nox, made use of talk to guide learners to think and talk about equivalent fractions. The study was framed by the concept of 'dialogic teaching', described here as a pedagogic approach underpinned by specific features enacted through a range of possible talk strategies. Analysis of both observational and interview transcripts revealed that her teaching approach could be classified as following the IRF format, despite her attempts to elicit learners' ideas on equivalent fractions.

Interview responses confirmed her allegiance to this format. However, her reasons for adopting this approach were found to be reasonable, given the work environment of a daily grind, in which she practised her craft. Professional development programmes can mitigate these obstacles by capacitating early career teachers with skills as they navigate their way in a teaching and learning environment such as that in which Nox found herself. The complexity of teaching notwithstanding, future studies must investigate the impact of the kind of environment in which early career teachers work as they form their styles and strategies of teaching. In particular, such studies may focus on the effect of the environment on early career teachers' ability to engage learners in meaningful learning, on a large scale (i.e. using survey methods).

\section{Acknowledgements}

I am particularly indebted to the Grade 4 early career teacher and her learners for opening their classroom and being generous with their time.

\section{Competing interests}

The author declares that he has no financial or personal relationships that may have inappropriately influenced him in writing this article.

\section{Author's contributions}

The corresponding author worked the manuscript from concept right up to its conclusion.

\section{Funding information}

This work was supported in part by the grant received from the University Capacity Development Programme (UCDP) at UKZN. 


\section{Data availability}

The data that support the findings of this study are available from the corresponding author upon reasonable request.

\section{Disclaimer}

Any opinions, findings, and conclusions or recommendations expressed in this article are those of the author and do not necessarily reflect the views of the UCDP.

\section{References}

Alexander, R.J. (2000). Culture and pedagogy: International comparisons in primary education. Oxford: Blackwell.

Alexander, R.J. (2006). Towards dialogic teaching: Rethinking classroom talk. Cambridge: Dialogos.

Alexander, R.J. (2020). A dialogic teaching companion (1st ed.). London: Routledge.

Aliustaoğlu, F., Tuna, A., \& Biber, Ç.A. (2018). Misconceptions of sixth grade secondary school students on fractions. International Electronic Journal of Elementary Education, 18(5), 591-599. https://doi.org/10.26822/iejee.2018541308

Arbaugh, J. B., \& Benbunan-Fich, R. (2006). An investigation of epistemological and social dimensions of teaching in online learning environments. Academy of Management Learning and Education, 5(4), 435-447. https://doi.org/10.5465/ Management Learning
amle.2006.23473204

Arend, B., \& Sunnen, P. (2015). Dialogic classroom talk - Rethinking 'messy' classroom interaction. Proceedings of the European Association for Practitioner Research on Improving Learning. Belval, Luxembourg: EAPRIL.

Ausubel, D.P. (2000). The nature of meaning and meaningful learning. In The acquisition and retention of knowledge: A cognitive view (pp. 67-100). Dordrecht: Springer.

Ausubel, D.P. (2012). The acquisition and retention of knowledge: A cognitive view. Dordrecht: Springer.

Bakhtin, M.M. (1981). The dialogic imagination: Four essays by M.M. Bakhtin. In M. Holquist (Ed.), C. Emerson \& M. Holquist, (Trans.). Austin, TX: University of Texas Press.

Bakhtin, M.M. (2010). Speech genres and other late essays. Austin, TX: University of Texas Press.

Baroody, A.J., \& Hume, J. (1991). Meaningful mathematics instruction: The case of fractions. Remedial and Special Education, 12(3), 54-68. https://doi. org/10.1177/074193259101200307

Braun, V., \& Clarke, V. (2006). Using thematic analysis in psychology. Qualitative Research in Psychology, 3(2), 77-101. https://doi.org/10.1191/1478088706qp063oa

Bright, G.W., Behr, M.J., Post, T.R., \& Wachsmuth, I. (1988). Identifying fractions on number lines. Journal for Research in Mathematics Education, 19(3), 215-232. https://doi.org/10.2307/749066

Carlsen, W.S. (1991). Subject-matter knowledge and science teaching. Advances in Research on Teaching, 2, 115-143.

Charalambous, C.Y., \& Pitta-Pantazi, D. (2007). Drawing on a theoretical model to study students' understanding of fractions. Educational Studies in Mathematics, study students' understanding of fractions. Educational Studies
$64(3), 293-316$. https://doi.org/10.1007/s10649-006-9036-2

Common Core State Standards Initiative [CCSSI]. (2010). Common Core State Standards for Mathematics (CCSSM). Washington, DC: National Governors Association Center www.corestandards.org/wp-content/uploads/Math_Standards.pdf

Cramer, K., \& Henry, A. (2002). The development of students' knowledge of fractions and ratios. In B. Litwiller, \& G. Bright (Eds.), Making sense of fractions, ratios, and proportions (pp. 3-17). Reston, VA: National Council of Teachers of Mathematics.

Cramer, K.A., Post, T.R., \& DelMas, R.C. (2002). Initial fraction learning by fourth- and fifth-grade students: A comparison of the effects of using commercial curricula with the effects of using the rational number project curriculum. Journal for Research in Mathematics Education, 33(2), 111-144. https://doi.org/10.2307/749646

Creswell, J.W. (2012). Educational research: Planning, conducting, and evaluating quantitative and qualitative research (4th ed.). Boston, MA: Pearson Education.

Davis, R.B., \& Maher, C.B. (1997). How students think: The role of representations. In L.D. English (Ed.), Mathematical reasoning, analogies, metaphors, and images (pp. 93-115). Hillsdale, NJ: Lawrence Erlbaum Associates.

Denzin, N.K., \& Lincoln, Y.S. (2011). The SAGE handbook of qualitative research (4th ed.). Thousand Oaks, CA: Sage.

Department of Basic Education [DBE]. (2011). Curriculum and assessment policy statement. Mathematics. Grades 1-3. Pretoria: DBE.

Fielden, A.L., Silence, E., \& Little, L. (2011). Children's understandings' of obesity, a thematic analysis. International Journal of Qualitative Studies on Health and Wellbeing, 6(3), 7170. https://doi.org/10.3402/qhw.v6i7170

Fusch, P.I., \& Ness, L.R. (2015). Are we there yet? Data saturation in qualitative research. Qualitative Report, 20(9), 1408-1416.

Gattegno, C. (2010). The common sense of teaching mathematics (2nd ed.). New York, NY: Educational Solutions Worldwide.
Gee, J.P. (2014). An introduction to discourse analysis: Theory and method. London: Routledge.

Hiebert, J., \& Grouws, D. (2007). The effects of classroom mathematics teaching on students' learning. In F.K. Leister (Ed.), Second handbook of research on mathematics teaching and learning (pp. 371-404). Reston, VA: National Council of Teachers of Mathematics.

Hogan, K.M., Nastasi, B.K., \& Pressley, M. (2000). Discourse patterns and collaborative scientific reasoning in peer and teacher-guided discussions. Cognitive and Instruction, 17(4), 379-432. https://doi.org/10.1207/S1532690XCI1704_2

Howitt, D., \& Cramer, D. (2005). Introduction to research methods in psychology. Harlow: Pearson.

Jackson, P.W. (2004). The daily grind. In D.J. Flinders, \& S.J. Thornton (Eds.), The curriculum studies reader (pp. 93-102). New York, NY: Routledge Falmer.

Jigyel, K., \& Afamasaga-Fuata'i, K. (2007). Students' conceptions of models of fractions and equivalence. Australian Mathematics Teacher, 63(4), 17-25.

Kerslake, D. (1986). Fractions: Children's strategies and errors - A report of the strategies and errors in secondary mathematics project. Windsor: NFER-Nelson.

Kilpatrick, J., \& Izsák, A. (2008). A history of algebra in the school curriculum. In C.E. Greenes (Ed.), Algebra and algebraic thinking in school mathematics: Seventieth yearbook (pp. 3-18). Reston, VA: National Council of Teachers of Mathematic.

Lamon, S. J. (2020). Teaching fractions and ratios for understanding: Essential content knowledge and instructional strategies for teachers (4th ed.). New York, NY: Routledge.

Lannin, J. K., Ellis, A. B., Elliott, R., \& Zbiek, R. M. (2011). Developing essential understanding of mathematical reasoning for teaching mathematics in prekindergarten-grade 8. Reston, VA: National Council of Teachers of Mathematics.

Lee, M.Y., \& Lee, J.-E. (2020). Spotlight on area models: Pre-service teachers' ability to link fractions and geometric measurement. International Journal of Science and Mathematics Education 19, 1079-1102. https://doi.org/10.1007/s10763-02010098-2

Lincoln, Y.S., \& Guba, E.G. (1985). Naturalistic inquiry (1st ed.). Newbury Park, CA: Sage.

Lortie, D.C. (1975). Schoolteacher: A sociological study. Chicago, IL: Universtity of Chicago Press.

Marmur, O., Yan, X., \& Zazkis, R. (2020). Fraction images: The case of six and a half. Research in Mathematics Education, 22(1), 22-47. https://doi.org/10.1080/1479 4802.2019.1627239

Mercer, N. (1995). The guided construction of knowledge: Talk among teachers and learners. Clevendon: Multilingual Matters.

Mercer, N., \& Littleton, K. (2007). Dialogue and the development of children's thinking: A sociocultural approach. London: Routledge.

Mercer, N., \& Sams, C. (2006). Teaching children how to use language to solve maths problems. Language and Education, 20(6), 507-528. https://doi.org/10.2167/ le678.0

Mortimer, E.F., \& Scott, P.H. (2003). Meaning making in secondary science classrooms. Berkshire: McGraw-Hill International.

Namkung, J.M., Fuchs, L.S., \& Koziol, N. (2018). Does initial learning about the meaning of fractions present similar challenges for students with and without adequate whole-number skill? Learning and Individual Differences, 61, 151-157. https://doi.org/10.1016/j.lindif.2017.11.018

Nathan, M.J., \& Knuth, E.J. (2003). A study of whole classroom mathematical discourse and teacher change. Cognition and Instruction, 21(2), 175-207. https://doi. org/10.1207/S1532690XC12102_03

National Council of Teachers of Mathematics [NCTM]. (2000). Principles and standards for school mathematics. Reston, VA: Author.

National Governors Association Center for Best Practices [NGA] \& Council of Chief State School Officers [CCSSO]. (2010). Retrieved May 29, 2019, from http://www. corestandards.org/Math/

Newton, D.P., \& Newton, L.D. (2007). Could elementary mathematics textbooks help give attention to reasons in the classroom? Educational Studies in Mathematics, 64(1), 69-84. https://doi.org/10.1007/s10649-005-9015-z

$\mathrm{Ni}$, Y., \& Zhou, Y.D. (2005). Teaching and learning fraction and rational numbers: The origins and implications of whole number bias. Educational Psychologist, 4O(1), 27-52. https://doi.org/10.1207/s15326985ep4001_3

Novak, J.D. (2002). Meaningful learning: The essential factor for conceptual change in limited or inappropriate propositional hierarchies leading to empowerment of learners. Science Education, 86(4), 548-571. https://doi.org/10.1002/ sce.10032

Novak, J.D. (2010). Learning, creating, and using knowledge: Concept maps as facilitative tools in schools and corporations. Journal of e-Learning and Knowledge Society, 6(3), 21-30. https://doi.org/10.4324/9780203862001

Nystrand, M. (1997). Dialogic instruction: When recitation becomes conversation. In M. Nystrand, A. Gamoran, R. Kachur, \& C. Prendergast (Eds.), Opening dialogue: Understanding the dynamics of language learning and teaching in the English classroom (pp. 1-29). New York, NY: Teachers' College Press.

Obersteiner, A., Alibali, M.W., \& Marupidi, V. (2020). Complex fraction comparisons and the natural number bias: The role of benchmarks. Learning and Instruction, 67, 101307. https://doi.org/10.1016/j.learninstruc.2020.101307

Önal, H., \& Yorulmaz, A. (2017). The errors made by primary school fourth graders on fractions. Journal of Research in Education and Society, 4(1), 98-113.

Organisation for Economic Co-operation and Development (OECD). (2005). Teachers matter: Attracting, developing and retaining effective teachers. Paris: OECD. 
Pappas, C.C., \& Varelas, M. (2006). Dialogic inquiry around information texts: The role of intertextuality in constructing scientific understandings in urban primary
classrooms. Linguistics and Education, 13(4), 435-482. https://doi.org/10.1016/ classrooms. Linguistics a
s0898-5898(03)00004-4

Patton, M.Q. (2002). Qualitative research and evaluation methods (3rd ed.). Thousand Oaks, CA: Sage.

Patton, M.Q. (2015). Qualitative research and methods: Integrating theory and practice. Thousand Oaks, CA: Sage.

Pearn, C. (2003). Fractions: Using the measurement model to develop understanding. In M. Goos \& T. Spencer (Ed.), Making waves (Proceedings of the 19th Biennial Conference of the Australian Association of Mathematics Teachers, Brisbane (pp. 404-410). Adelaide: AAMT.

Pedersen, P.L., \& Bjerre, M. (2021). Two conceptions of fraction equivalence. Educational Studies in Mathematics, 107(1), 135-157. https://doi.org/10.1007/ s10649-021-10030-7

Piaget, J. (1964). Development and learning. Journal of Research in Science Teaching, $40, \mathrm{~S} 8-\mathrm{S} 18$.

Putra, Z.H., \& Winsløw, C. (2018). Teachers' collective knowledge: The case of equivalent fractions. The 6th South East Asia Design Research International Conference (pp. 1-6), Banda Aceh, 27-28 June.

Reid, D.A. (2002). Conjectures and refutations in Grade 5 mathematics. Journal for Research in Mathematics Education, 33(1), 5-29. https://doi.org/10.2307/749867

Resnick, L.B., Asterhan, C.S., \& Clarke, S.N. (2015). Talk, learning and teaching. In L.B. Resnick, C.S. Asterhan, \& S.N. Clarke (Eds.), Socializing intelligence through academic talk and dialogue (pp. 1-12). Washington, DC: AERA.

Rojas-Drummond, S., \& Mercer, N. (2004). Scaffolding the development of effective collaboration and learning. International Journal of Educational Research, 39, 99-111.

Rojas-Drummond, S., Mercer, N., \& Dabrowski, E. (2001). Collaboration, scaffolding and the promotion of problem solving strategies in Mexican pre-schoolers. European Journal of Psychology of Education, 16(2), 179-196. https://doi. org/10.1007/BF03173024

Saunders, B., Sim, J., Kingstone, T., Baker, S., Waterfield, J., Bartlam, B., ... Jink, C. (2018). Saturation in qualitative research: Exploring its conceptualization and operationalization. Quality \& Quantity, 52(4), 1893-1907. https://doi. org/10.1007/s11135-017-0574-8

Schmidt, H. G. (1993). Foundations of problem-based learning: Some explanatory notes. Medical Education, 27(5), 422-432. https://doi.org/10.1111/j.13652923.1993.tb00296x
Scott, P.H., Mortimer, E.F., \& Aguiar, O.G. (2006). The tension between authoritative and dialogic discourse: A fundamental characteristic of meaning making interactions in high school science lessons. Science Education, 90(4), 605-631. interactions in high school science
$\mathrm{https} / / /$ doi.org/10.1002/sce.20131

Shongwe, B. (2014). Understanding teacher communication patterns: Case studies of talk in new teachers' science classrooms. Master's dissertation, Faculty of Science, University of the Witwatersrand, Johannesburg.

Sinclair, J.M., \& Coulthard, M. (1975). Towards an analysis of discourse: The English used by teachers and pupils. London: Oxford University Press.

Skidmore, D. (2006). Pedagogy and dialogue. Cambridge Journal of Education, 36(4), 503-514. https://doi.org/10.1080/03057640601048407

Tatto, M.T., Rodriguez, M.C., Smith, W.M., \& Reckase, M.D. (Eds.). (2018). Exploring the mathematics education of teachers using TEDS-M data. Dordrecht: Springer.

Van de Walle, J.A., Bay-Williams, J.M., Lovin, L.H., \& Karp, K.S. (2013). Teaching student-centered mathematics: Developmentally appropriate instruction for grades 6-8 (2nd ed., Vol. III). Essex: Pearson Education.

Van der Linden, J., \& Renshaw, P. (2004). Dialogic learning: Shifting perspectives to learning, instruction, and teaching. Dordrecht: Kluwer Academic.

Van Hoof, J., Lijnen, T., Verschaffel, L., \& Van Dooren, W. (2013). Are secondary schoo students still hampered by the natural number bias? A reaction time study on fraction comparison tasks. Research in Mathematics Education, 15(2), 154-164. https://doi.org/10.1080/14794802.2013.797747

Vygotsky, L.S. (1978). Mind in society: The development of higher psychological processes. Cambridge, MA: Harvard University Press.

Watson, A., \& Mason, J. (2005). Mathematics as a constructive activity: Learners generating examples. Mahwah, NJ: Lawrence Erlbaum.

Wells, G. (1999). Dialogic inquiry: Towards a sociocultural practice and theory of education. Cambridge: Cambridge University Press.

Wessel, L. (2020). Vocabulary in learning processes towards conceptual understanding of equivalent fractions: Specifying students' language demands on the basis of lexical trace analysews. Mathematics Education Research Journal, 32, 653-681. https://doi.org/10.1007/s13394-019-00284-z

Wong, M. (2010). Equivalent fractions: Developing a pathway of students' acquisition of knowledge and understanding. In B. Kissane \& C. Hurst (Eds.), Proceedings of the 33rd Annual Conference of the Mathematics Education Research Group of Australasia (pp. 673-680). Fremantle: MERGA. 